J. Lake Sci.(湖泊科学), 2009, 21(2): 143-158

http://www.jlakes.org. E-mail: jlakes@niglas.ac.cn

(C2009 by Journal of Lake Sciences

\title{
湖泊水色遥感研究进展
}

马荣华 ${ }^{1}$, 唐军武 ${ }^{2}$, 段洪涛 ${ }^{1}$, 潘德炉 ${ }^{3}$

(1: 中国科学院南京地理与湖泊研究所, 南京 210008)

(2: 国家卫星海洋应用中心, 北京 100081)

(3: 卫星海洋环境动力学国家重点实验室, 国家海洋局第二海洋研究所, 杭州 310012)

摘 要: 从卫星传感器、大气校正、光学特性测量、生物光学模型及水体辐射传输、水质参数反演方法等方面, 系统分析了 湖泊水色遥感的发展现状. 湖泊水体物质组份的复杂性以及卫星传感器与实际需求的矛盾决定了湖泊水色遥感的难度. 目前 湖泊水色遥感在一些关键问题上仍没有实质性进步, 离水色遥感监测的业务化尚有一段距离. 令人欣慰的是, 卫星传感器以 及水色遥感反演算法的不断发展和进步, 让我们看到了胜利的曙光.

关键词: 湖泊; 水色; 水质; 遥感

\section{Progress in lake water color remote sensing}

\author{
MA Ronghua ${ }^{1}$, TANG Junwu ${ }^{2}$, DUAN Hongtao ${ }^{1} \&$ PAN Delu $^{3}$ \\ (1: Nanjing Institute of Geography and Limnology, Chinese Academy of Sciences, Nanjing 210008, P.R.China) \\ (2: National Satellite Ocean Application Service, Beijing 100081, P.R.China) \\ (3: Second Institute of Oceanography, State Oceanic Administration, Hangzhou 310012, P.R.China)
}

Abstract: We analyzed in detail the status quo of lake water color remote sensing from some aspects of satellite sensor, atmospheric correction, optical properties measurement, bio-optical model, radiative transfer model for the waters, and water quality parameter retrieval approach. It has a great difficulty to have practical application of water color remote sensing at a regional scale at present, depending on the complex components of lake water and on the inconsistency between satellite sensor and its actual demand from water quality monitoring. The progress in some key problems for lake water color remote sensing is still small, and there is a long way to go in applications of lake water color remote sensing. However, to be greatly pleasure, the satellite sensor and water color parameter retrieval approach are developing and making progresses, and the application in the future is hopeful.

Keywords: Lake; water color; water quality; remote sensing

水色遥感最初发展并应用于海洋水体, 称为海洋水色遥感. 随着内陆湖泊生态环境问题的逐渐突出, 海洋水色遥感的理论和技术被用于内陆湖泊水体, 并得到了进一步的丰富和发展，称为湖泊水色遥感， 是指利用各种星载传感器探测与反演内陆湖泊水体水色要素参数(主要指叶绿素、悬浮物、溶解性有机物 等)的一门以现实需求为导向的实用性应用科学, 属于定量遥感的研究范畴, 但与湖泊物理以及湖泊化学 等多学科交叉. 与海洋水色遥感相比, 湖泊水色遥感在理论、技术、方法和手段上与其一脉相承, 但由于 具有更为复杂的研究对象, 问题的解决具有更大的挑战性, 是对海洋水色遥感理论和方法的丰富和发展. 另外, 湖泊水色遥感不同于湖泊水质遥感, 前者是后者的基础和前提, 后者不仅仅局限于水色要素参数, 还包括能够用来评价水质的其它参数(如总氮、总磷、富营养化指数等), 但由于其它水质参数不能或很难 通过遥感手段来直接获取和反演, 因此湖泊水质遥感的本质仍是湖泊水色遥感, 也有学者把湖泊水色遥 感称为湖泊水质遥感. 湖泊水色遥感的首要目标是通过卫星遥感影像高精度获取水体的离水辐亮度或遥 感反射率, 最终目标是通过离水辐亮度或遥感反射率反演水体的水色要素参数浓度, 以满足湖泊水体水

* 国家自然科学基金(40871168,40671138,40801137)资助. 2008-11-03 收稿; 2008-12-03 收修改稿. 马荣华, 男, 1972 年生, 研究员; E-mail: rhma@niglas.ac.cn. 
质监测与预测预警的现实需求. 与陆地定量遥感相比, 湖泊水色遥感的应用目标更为具体和明确, 但面 临更多的科学问题, 具有更大的挑战性, 涉及水-气和水-底等两个界面转换过程以及水体和大气等两个 辐射传输过程. 近年来, 我国湖泊水色遥感发展迅速 ${ }^{[1]}$, 一方面得益于遥感技术本身的迅猛发展, 另一方 面受到现实需求(即湖泊生态环境的日益突出推动着湖泊水质监测手段的不断革新)的强烈推动. 湖泊作 为流域系统内的重要单元, 承载并始终参与了全球气候变化过程, 是全球气候变化区域响应的一个重要 记录器, 水色遥感作为记录器中参数提取的一个重要手段, 将发挥越来越重要的作用. 另外, 湖泊水色遥 感模型与地球系统科学的其它模型 (如湖泊水生态模型、湖泊水动力模型等)相结合, 将一并纳人相关行业 领域的业务化模式中, 共同服务于湖泊水体污染事件的预测预警.

\section{1 发展与现状}

卫星遥感具有快速、大范围、周期性、一次成像成本相对低廉的特点，是湖泊水色遥感的实用基本 平台, 其本质是通过遥感影像数据反演湖泊水体的水色参数含量, 反演的过程就是模型的求解过程, 反 演的精度一方面取决于传感器本身的能力 (时间分辨率、空间分辨率、光谱分辨率以及辐射分辨率等), 另 一方面取决于模型的细部刻画能力, 反演模型成为湖泊水色遥感的核心和关键, 模型的构建过程也称为 湖泊水色遥感的正演过程, 是领域研究者的焦点关注内容, 始终贯穿于湖泊水色遥感的整个发展历程, 涉及的对象包括大气、水体、水气界面, 光学浅水区还涉及水底底质, 关注的内容包括适合湖泊水体水 色遥感的大气校正、水-气或气-水界面校正、生物光学模型的构建, 光学浅水区还包括水底信号的分离 和剔除. 因此湖泊水色遥感是大气辐射传输过程和水体辐射传输过程的高度集合体. 针对海洋水体, 国 外已经基本建立了海洋-大气耦合矢量辐射传输模型, 如 $\mathrm{COART}^{[2]}$ 和 $\mathrm{MOMO}^{[3]} \mathrm{OSOA}^{[4]}$, 但均只考虑了 标量辐射传输问题; 我国在这方面有了较大进展, 何贤强等 ${ }^{[5]}$ 利用矩阵算法开发了较为完备的海洋-大气 耦合矢量辐射传输数值计算模型 PCOART. 在适合湖泊水体的生物光学模型的支持下, 适当改进后, 这 些耦合大气-水体辐射传输模型也可以用于湖泊水体.

\section{1 卫星传感器}

海洋 I 类水体的水色遥感有着专门的水色传感器, 如 CZCS(1978-1986 年)、SeaWiFS(1997 年至今)、 MODIS(1999 年至今)、MERIS(2002 年至今)、GLI 以及我国 HY-1 A/B 上的 COCTS(2002 年至今)等. 湖 泊水体面积很小, 即使我国最大的湖泊一一青海湖, 面积也仅约有 $4500 \mathrm{~km}^{2}$, 那些专用的海洋水色传感器 虽然在光谱分辨率、时间分辨率以及信噪比等方面具有极大的优势, 但空间分辨率普遍不高, 如最常用 的 MODIS 的最高空间分辨率也仅有 $250 \mathrm{~m}$, 极大地限制了这些传感器在湖泊水色遥感中的实际应用. 目 前还没有一个专门的湖泊水色遥感传感器 ${ }^{[6]}$, 湖泊水色/水质遥感主要使用陆地卫星多光谱传感器, 如 Landsat TM/ETM、SPOT HRV、CBERS CCD、EO-1 ASTER、Beijing-1 CCD 等, 这些卫星传感器具有较 高的空间分辨率(20-30m 左右), 但时间分辨率较低(15-30d), 难以及时扑提湖泊水体的污染事件, 对整 个污染过程不能形成有效监测, 实用性受到很大的限制. 另外, 水质参数的定量反演需要较为精细的光 谱分辨率(10nm 左右), 高光谱遥感随之引起了领域专家学者的重视 ${ }^{[7]}$, 如星载高光谱传感器 EO-1 Hyperion ${ }^{[8-10]}$ 以及机载高光谱传感器 AVIRIS ${ }^{[11]} 、 \mathrm{OMIS}^{[12]} 、 \mathrm{CASI}^{[13]} 、 \mathrm{AISA}^{+[14]}$ 等, 但高光谱传感器信噪 比一般较低, 很难满足水色遥感的要求, 另外高光谱传感器刈幅较窄 (如 Hyperion 仅 7.5km), 很难满足湖 泊水体污染监测的实际需求. 太湖蓝藻遥感日常监测的实践经验告诉我们, 对湖泊水体 (或小面积水体) 水质(污染)监测而言, 在选择卫星传感器时, 如果不能同时满足高时间分辨率、高空间分辨率和高光谱分 辨率的要求, 首先要考虑的是时间分辨率, 其次是空间分辨率, 然后才是光谱分辨率, 因此 MODIS 250m 的卫星影像数据在太湖蓝藻遥感监测中得到了实际应用, 它充分体现了卫星遥感的快速、大范围和周期 性的特点. 可喜的是, 我国的环境与灾害监测预报小卫星(A、B 星)已经成功发射升空, 携带的光学传感器 具有高空间分辨率 $(20-30 \mathrm{~m})$ 、高时间分辨率 $(2 \mathrm{~d})$ 、高光谱分辨率 $(0.45-0.95 \mu \mathrm{m}$ 波谱范围内 128 个波段)以 及宽观测幅宽 $(720 \mathrm{~km})$ 的性能, 将有效提高湖泊水体水色遥感反演的能力和水平.

\section{2 大气校正}

卫星传感器接收到的信号为大气顶层的总辐亮度, 其中来自水体的离水辐射约占 $10 \%$, 大气的程辐 
射约占 $90 \%{ }^{[15]}$, 水体信息的小信号信息几乎淹没在大气中; Gordon 的研究表明 ${ }^{[16]}$, 当叶绿素浓度由 $0.01 \mathrm{mg} / \mathrm{m}^{3}$ 变化到 $10.0 \mathrm{mg} / \mathrm{m}^{3}$ 时, 遥感器接收的大气顶层总信号几乎没有变化, 仅从大气顶层总信号中很 难准确反映水体的物质组分含量变化, 因此大气影响的剔除在水色遥感反演中显得尤为重要, 大气校正 成为水色遥感的关键技术 ${ }^{[17]}$.

水色遥感信号最终反映在卫星传感器获得的某一通道(中心波长 $\lambda_{i}$ )接收的大气顶层 $(\mathrm{TOA})$ 辐亮度 $L_{\mathrm{t}}\left(\lambda_{i}\right)$, 包括由大气散射和水面对天空光的镜面反射引起的程辐射 $L_{\mathrm{path}}\left(\lambda_{i}\right)$ (包含瑞利散射 $L_{\mathrm{r}}\left(\lambda_{i}\right)$ 和气溶胶散 射 $L_{\mathrm{a}}\left(\lambda_{i}\right)$ )、由水面对直射太阳光的镜面反射引起的太阳耀光 $L_{\mathrm{g}}\left(\lambda_{i}\right)$ 、由直射太阳光和天空光引起的水面白 帽反射 $L_{\mathrm{wc}}\left(\lambda_{i}\right)$ 以及来自水体的离水辐亮度 $L_{\mathrm{w}}\left(\lambda_{i}\right)$, 在光学浅水中, 也包括来自水底的贡献 $L_{\mathrm{b}}\left(\lambda_{i}\right)$, 即来自水 体和水底的总贡献为 $L_{\mathrm{wb}}\left(\lambda_{i}\right)$; 水体离水辐亮度和白帽贡献可近似认为均匀角分布, 采用大气漫射透过率 $t$; 太阳耀斑分布具有很强的方向性(极大风速除外), 采用大气直射透过率 $T$; 因此有 (为简便, 省略 $\lambda_{i}$ ):

$$
L_{\mathrm{t}}=L_{\mathrm{path}}+T L_{\mathrm{g}}+t L_{\mathrm{wc}}+t L_{\mathrm{w}}+t L_{\mathrm{b}}=L_{\mathrm{path}}+T L_{\mathrm{g}}+t L_{\mathrm{wc}}+t L_{\mathrm{wb}}
$$

海洋水色传感器具有侧视扫描装置, 能避免太阳耀光; 其它陆地卫星如 Landsat TM/ETM 传感器, 只 要观测时的太阳天顶角不是很小, 就不会接收到太阳耀光, 因此 $L_{\mathrm{g}}$ 可以忽略. 另外, 在低风速的情况下, 由水面白帽对直射太阳光和天空光引起的 $L_{\mathrm{wc}}$ 也可以忽略. 无论是单散射还是包含多次散射和偏振作用 的 Rayleigh 散射, $L_{\mathrm{r}}$ 都已有比较精确的算法 ${ }^{[18-24]}$, 关键在于 $L_{\mathrm{a}}$ 的计算, 有效分离包含水体信息的离水辐射 信号和大气气溶胶散射信号. 大洋开阔水体 ( I 类水体)的大气校正基于近红外波段离水辐射为 0 的假设, 较 易获取近红外波段的气溶胶散射项 $\left(L_{\mathrm{t}}-L_{\mathrm{r}}\right)$, 之后根据气溶胶散射的光谱变化关系，外推到可见光波段， 从而得到各个可见光波段的离水辐射值, 并可生成精确瑞利散射查找表、气溶胶散射查找表及大气漫射 透过率查找表，称为基于精确近红外迭代关系的大气校正方法，该方法大气校正的精度较高，如国际上 通用的 Gordon 标准算法在海洋 I 类水体中可达 95\% ${ }^{[21]}$, 已经实现了业务化运行, 如 CZCS 的业务化大气 校正、SeaWiFS 的业务化大气校正以及 MODIS 的业务化大气校正、HY-1 的业务化大气校正等.

湖泊水体受人类活动的影响更为强烈, 物质陆源较多; 不同的湖泊, 水质、物质组成等差异较大, 近 红外波段散射特性的变化具有很大的不确定性; 湖泊水体面积一般较小, 受陆地的影响, 气溶胶变化较 为强烈，而水体在近红外波段的信号很弱，难以准确测量; 另外，湖泊中存在大面积的光学浅水，离水辐 射除包含来自水体的贡献外，也包含来自湖底底质的贡献 ${ }^{[25]}$. 因此近红外波段离水辐射为 0 的假设将导 致所有波段总吸收系数偏小而散射系数偏大 ${ }^{[26]}$, 高精度地获取近红外波段水体离水辐射的迭代关系存在 很大困难, 适用于大洋开阔水体的大气校正假设不再适用于内陆湖泊水体, 基于精确近红外迭代关系的 大气校正方法受到很大挑战.

最初, 陆地遥感的大气校正方法也应用于湖泊水色遥感, 其中基于辐射传输的大气校正模型应用尤 为广泛，主要包括 LOWTRAN、MODTRAN、5S、6S、ACORN、FLAASH、ATREM 以及 HATCH 等，这 些大气辐射传输模型一般需要输人卫星传感器过境时的气温、气压、水汽含量、臭氧含量、能见度、灰 尘颗粒度等, 但同步实地观测非常困难、需要耗费大量的人力物力, 且对历史数据无能为力, 因此实时的 遥感大气校正非常困难 ${ }^{[27]}$. 为此, $6 \mathrm{~S}$ 和 MODTRAN 提供了一系列基于大量观测数据统计分析得到的既定 参数, 这些参数必然与实际的大气状况存在较大差别, 从而严重影响了基于辐射传输的大气校正精度, 不能实现大气校正的业务化运行, 不适用于湖泊水色遥感. 为此, 国际水色遥感界提出了多种针对“亮像 元”(即近红外离水辐射非零)的大气校正算法, 但基本还处于区域性试验阶段, 主要包括: (1)Arnone 迭代 法. Arnone ${ }^{[28]}$ 基于红光和近红外波段的总吸收系数主要决定于纯水的吸收系数以及颗粒物后向散射在红 外近红外波段范围内随光谱线性变化的假设, 使用简化的生物光学模型即 $R_{\mathrm{rs}}(\lambda)=0.051 b_{\mathrm{bp}}(\lambda) / a_{\mathrm{w}}(\lambda)$ 进行离 水辐亮度和气溶胶的迭代求解. (2)邻近清洁水体象元法. $\mathrm{Hu}$ 等 ${ }^{[29]}$ 以气溶胶类型在较小的空间范围内 (大约 50-100km)保持不变为假设条件, 利用邻近清洁水体象元法来确定混浊区域的气溶胶类型, 从而解决了 近岸混浊水体 SeaWiFS 图像的大气校正问题. (3)Ruddick 等 ${ }^{[30}$ 假设气溶胶多次散射和气溶胶-大气分子相 互作用之和在 $765 \mathrm{~nm}$ 和 $865 \mathrm{~nm}$ 波段的比值具有空间一致性(即在一幅影像上为常数), 同时假设离水辐射 反射率经太阳-海面大气透过率修正后, 在上述两个波段的同一幅影像内亦为一常数, 将上述两个常数 带人相应波段的去瑞利散射和白帽修正后的传输方程, 求得气溶胶散射项, 最后按照 Gordon 标准算法求 
解; 以该算法为基础, 韦钧等 ${ }^{[31]}$ 和李花 ${ }^{[32]}$ 均假设 765 和 $865 \mathrm{~nm}$ 波段处气溶胶多次散射之比和离水辐射率 之比为常数, 发展了针对珠江口 II 类水体的大气校正算法. (4)神经网络法. Doerffer and Schiller ${ }^{[33]}$ 和 Schiller and Doerffer ${ }^{[34]}$ 使用人工神经网络模型，利用模拟的 MERIS 16 个波段的大气顶层去瑞利散射后的 反射率数据集, 同时反演大气气溶胶和 3 要素(叶绿素、悬浮物和 DOC)浓度; 该模型把大气校正和水色 遥感反演当作一个整体, 适用于较大范围内的贫营养 I 类水体和混浊 II 类水体. 詹海刚等 ${ }^{[35]}$ 建立了利用 遥感反射比反演叶绿素浓度的神经网络模型, 反演精度优于统计算法. Zhang 等 ${ }^{[36]}$ 使用 Landsat TM 和 ERS-2 SAR 卫星影像数据建立了主要水质参数含量的神经网络模型, 结果表明神经网络算法的精度高于 经验回归模型. 丁静 ${ }^{[37]}$ 利用神经网络模型实现了黄东海区大气校正和水色物质浓度的一并反演. (5)主成 分分析法. Neumann 等 ${ }^{[38]}$ 使用该方法, 首先对卫星大气顶层辐亮度或反射率进行主成分分析, 根据各因 子的贡献, 确定用来进行成分浓度和气溶胶光学厚度反演的波段组合, 然后同时反演大气参数和水体成 分浓度; Neumann and Krawczyk ${ }^{[39]}$ 针对 IRS 数据, 再次使用主成分分析法同时进行大气校正和水色反演. (6)综合切换法. 丁静等 ${ }^{[40]}$ 把中国近岸水体划分为清洁 I 类水体、中低混浊水体和中高混浊水体等 3 类; 在清洁 I 类水体中采用 Gordon 标准算法, 在中低浑浊水体中采用 Arnone 迭代算法, 在中高浑浊水体中 采用优化算法. 另外, $\mathrm{He}$ 等 ${ }^{[41]}$ 利用高浑浊水体蓝紫光波段离水辐亮度相对较小的特点, 提出了一种利用 蓝紫光波段辅助近红外波段的浑浊水体大气校正算法; 有模拟研究表明 ${ }^{[42-43]}$, 这种在蓝紫光波段的配合 下，通过短波近红外波段的大气校正方法非常适合于湖泊等 II 类水体的水色遥感大气校正.

\section{3 光学特性测量}

水体辐射传输是水色遥感的基础理论之一, 其核心是生物光学模型, 生物光学模型的基础是水体的 两大光学特性, 即表观光学特性(AOPs, 也称表观光学量)和固有光学特性(IOPs, 也称固有光学量), 特别 对内陆湖泊等 II 类水体而言, 其中涉及的参数具有很强的区域性, 增加不同区域内水体光学特性的测量 既是模式参数化的重要步骤, 又是提高生物光学模型精度的有效方法 ${ }^{[44-45]}$. 表观光学特性是指随光照条 件变化而变化的量, 包括离水亮度 $\left(L_{\mathrm{w}}\right)$ 、归一化离水辐亮度 $\left(L_{\mathrm{wN}}\right)$ 、遥感反射比 $\left(R_{\mathrm{rs}}\right)$ 以及刚好处于水面以下 深度的辐照度比 $\left(R\left(0^{-}\right)\right)$等. 固有光学特性是指只与水体成分有关而不随光照条件变化而变化的量, 主要 指吸收系数和体散射函数, 或单位吸收系数和散射相函数.

表观光学特性的核心是离水辐亮度或遥感反射比, 测量方法有两种, 即剖面测量法以及水面以上测 量法. 水面以上测量法是 NASA SeaWiFS 测量规范推荐的一种测量方法, 目前已经较为成熟, 特别适合 于湖泊水体. 水面以上测量法最适合的测量仪器为双通道地物光谱仪, 如美国 ASD 公司 FieldSpec ${ }^{\circledR}$ Pro Dual VNIR 光谱辐射计(波长范围 350-1050nm) ${ }^{[46]}$, 可以同时测量天空光信号和水体信号, 详细的测量步 骤及注意事项参见相关文献 ${ }^{[47-48]}$.

现场固有光学特性测量包括吸收系数、后向散射系数和衰减系数等 3 个部分, 国际上自 20 世纪 90 年代开始, 特别在测量仪器方面已有较大发展. 最初的测量仪器对光学特性参数 (吸收系数和衰减系数) 的测量是独立的、非同步的, 后来发展到可以多光谱同时测量水体的吸收系数和衰减系数, 如现场用于 吸收系数测量的 AC-9(美国 Wetlabs 公司, 9 通道双光路吸收系数与光束衰减系数测量仪, 9 个通道分别位 于 $412 、 440 、 488 、 510 、 532 、 555 、 650 、 676$ 以及 $715 \mathrm{~nm}$ 处), 目前已有仪器可以实现吸收/衰减的高光 谱测量, 如 AC-S(美国 Wetlabs 公司, 高光谱双光路吸收系数与光束衰减系数测量仪, 85 个通道, 波长范 围: 400-750nm), 其中 AC-9 是得到 NOAA 和 NASA 有关方面推荐的商业化仪器, 在现场测量方面得到 了广泛的认同 ${ }^{[49]}$. 实验室内可用分光光度计测量水体各组分的吸收系数, 包括浮游植物色素吸收 $a_{\mathrm{ph}}(\lambda)$ $\left(\mathrm{m}^{-1}\right)$ 、非色素颗粒物吸收 $a_{\mathrm{d}}(\lambda)\left(\mathrm{m}^{-1}\right)$ 以及 CDOM 吸收 $a_{\mathrm{g}}(\lambda)\left(\mathrm{m}^{-1}\right)$, 吸收具有加和性 ${ }^{[50]}$, 同时参照已有的纯 水吸收系数 $a_{\mathrm{w}}(\lambda)\left(\mathrm{m}^{-1}\right)$ 的测量结果 ${ }^{[51-53]}$, 可以获取水体的总吸收系数 $\left(a(\lambda)=a_{\mathrm{ph}}(\lambda)+a_{\mathrm{d}}(\lambda)+a_{\mathrm{g}}(\lambda)+a_{\mathrm{w}}(\lambda)\right)$. 分光 光度计测量水体各组分吸收系数的详细步骤及注意事项可参见相关文献 ${ }^{[25,47,54]}$.

目前获取后向散射的方法主要有两种: (1)理论计算法. 一种是直接利用 Mie 散射理论, 在一定的假 设条件下, 直接计算水中颗粒的散射系数 $b(\lambda)\left(\mathrm{m}^{-1}\right)$ 或后向散射系数 $b_{\mathrm{b}}(\lambda)\left(\mathrm{m}^{-1}\right), b_{\mathrm{b}}=b_{\mathrm{bp}}+b_{\mathrm{bw}}$. 其中, $b_{\mathrm{bp}}$ 为颗 粒物的后向散射系数 $\left(\mathrm{m}^{-1}\right), b_{\mathrm{bw}}$ 为纯水的后向散射系数 $\left(\mathrm{m}^{-1}\right)$, 但由于不同的水体具有不同的颗粒属性如组 成、形状、尺寸、折射指数等, 因此通过理论模型来计算后向散射系数非常困难; 另一种是现场实测水 
体不同深度的向上和向下辐照度, 利用辐射传输模型, 建立相关方程, 求解后向散射系数 $b_{\mathrm{b}}(\lambda)$; (2)直接 测量法. 即使用光学仪器现场测定法, 一种是多角度进行体散射函数 $\beta(\psi, \lambda)$ 测量, 积分后获取后向散射系 数 $b_{\mathrm{b}}(\lambda)$, 代表性的仪器如 GASM ${ }^{[55]}$ 以及体散射仪 ${ }^{[56]}$, 这种方法较为准确, 但受时间以及深度的限制; 实 际上, 在后向散射方向上总存在一个角度 $\psi_{0}$, 使得 $\beta\left(\psi_{0}, \lambda\right) / b_{\mathrm{b}}$ 接近常数, 利用这个原理可以首先测量 $\beta\left(\psi_{0}, \lambda\right)$, 然后计算得到 $b_{\mathrm{b}}(\lambda)$. 根据这个原理, 后向散射系数测量仪器不断涌现, 测量通道也在不断增加, 从最初的 2 通道一直增加到现在的 9 通道, 如 HydroScat 系列的 HydroScat-2(420 和 700nm)、 HydroScat-4(420、470、532 和 700nm)以及 HydroScat-6(420、442、470、510、590 和 700nm), Wetlabs ECO 系列的 BB-3(470、532 和 $660 \mathrm{~nm}) 、$ BB-9(412、440、488、510、532、595、660、676 和 $715 \mathrm{~nm})$. 但这些 仪器测量前的校准、定标要求较为严格. 在后向散射系数的测量过程中, 为补偿光衰减而引起的数值低 估, 一般都要使用后向散射概率 $\left(\tilde{b}_{\mathrm{b}}\right)$, 即后向散射与总散射的比值 $\left(b_{\mathrm{b}} / b\right)$, 进行后向散射系数校正 ${ }^{[25,57]}$, 校正时一般假设后向散射概率为已知量, 因此后向散射概率影响着后向散射系数的现场测量精度. 然而 不同的水体, 后向散射概率有着较大的差异. 大洋开阔水体中, 后向散射概率 $b_{\mathrm{b}} / b$ 基本稳定, HS-6 默认为 $0.015^{[58]}, \mathrm{Kirk}^{[59]}$ 认为对许多沿岸和中混浊水体而言, 0.019 较为适合; Whitlock 等 ${ }^{[60]}$ 认为混浊河水的后向 散射概率大约为 0.059 ; Aas 等 ${ }^{[61]}$ 的研究表明, $b_{\mathrm{bp}} / b_{\mathrm{p}}$ 与悬浮颗粒大小有关, 颗粒越小, $b_{\mathrm{bp}} / b_{\mathrm{p}}$ 越大, 一般在 0.017 到 0.029 之间变化, 上限为 0.5 . 马荣华等 ${ }^{[62]}$ 以及 $\mathrm{Ma}$ 等 ${ }^{[63]}$ 通过现场测量, 结合优化算法, 发现太湖 水体的颗粒物后向散射概率不是一个定值，而是一个可以表示为波长的二次函数，在 442、488、532、589、 676 和 $852 \mathrm{~nm}$ 处分别为 $0.017 、 0.017 、 0.027 、 0.033 、 0.054$ 和 $0.094,400-900 \mathrm{~nm}$ 范围内均值为 $0.041 \pm 0.030$, 400-700nm 范围内均值为 $0.030 \pm 0.015$. 另外, 以现场实测获取的遥感反射比和实验室获取的各组分吸 收为基础, 通过生物光学模型, 利用最小二乘法, 可以模拟获得水体的后向散射系数 ${ }^{[62-64]}$.

海洋开阔水体 (I 类水体)中, 影响光学特性的物质组成较为简单(主要是叶绿素), 国际上针对 SeaWiFS 的表观光学量和固有光学量的观测和分析有比较成熟的规范标准 ${ }^{[47]}$, 我国在海洋水体光学特性 的测量、分析与应用方面做了大量工作, 并取得了丰硕成果 ${ }^{[48,54,65-73]}$. 内陆湖泊等 II 类水体中, 物质组成 较为复杂, 包含浮游植物色素、悬浮颗粒以及黄色物质等, 引起的光学特性远比 I 类水体复杂的多. 目前 为止, 对于湖泊水体水质参数估测使用的半分析方法所依赖的水体固有光学特性的认识仍旧比较肤浅, 一定程度上限制了这一方法在湖泊水体中的实际应用. 国外在这方面作了大量工作，欧洲 SALMON计划 项目 ${ }^{[44]}$ 测量调查了欧洲几个典型湖泊(如瑞典的 Erken, Vättern, Mälaren 湖)的固有光学特性(吸收和散射),

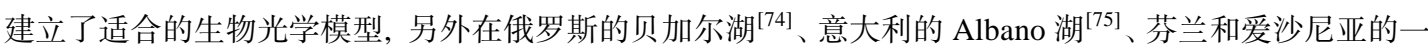
些湖泊 ${ }^{[76-77]}$ 、Chilko 湖 ${ }^{[78]}$ 以及美国的安大略湖 ${ }^{[79]}$ 都进行过固有光学特性测量.

借鉴 NASA SeaWiFS 测量规范, 我们已经掌握了物质组成复杂水体固有光学特性测量的基本方法, 并成功应用于太湖 ${ }^{[25,45,62-63,80-89]}$ 、青海湖 ${ }^{[90-91]}$ 、石头口门水库 ${ }^{[92]}$, 其中太湖的相关工作较为深人, 并形成 了良好的研究基础. Ma 等 ${ }^{[25,45]}$ 于 2004 年首次对太湖进行大规模综合光学特性测量, 获取了适合太湖水体 的三要素吸收光谱模型参数, 并基于三要素吸收对总吸收的贡献, 把太湖水体划分为 7 种类型: (1)CDOM 和非藻类颗粒主导型, (2)CDOM、非藻类颗粒和纯水主导型, (3)CDOM 和纯水主导型, (4)CDOM、浮游植 物颗粒和非藻类颗粒主导型, (5)非藻类颗粒主导型, (6)浮游植物颗粒和非藻类颗粒主导型, (7)浮游植物 颗粒、藻类颗粒和纯水主导型; 同时给出了太湖不同浑浊程度水体的后向散射特性 ${ }^{[63,84]}$. 以此为基础, 初 步确定了适合太湖光学深水的生物光学模型及其模型参数 ${ }^{[45]}$. 随后, 张兵等 ${ }^{[89]}$ 再次对太湖进行大规模综 合遥感试验. 太湖的多次实测结果表明, 内陆湖泊等 II 类水体的生物光学特性具有一定的季节性差异. 乐成峰等 ${ }^{[87]}$ 以太湖梅梁湾水体为对象, 对固有光学特性的季节性差异进行了较为详细地分析.

\section{4 生物光学模型及水体辐射传输}

水体辐射传输是水色谣感的基础理论之一. 国际上已经开发了多个水体辐射传输模型, 著名的如 Hydrolight 辐射传输模型以及 Monte Carlo 辐射传输模型, 可以应用于湖泊水色遥感的研究中. 湖泊水体 水深较浅, 既存在光学深水 (即遥感反射比不受底质影响的水体或者水深大于光穿透深度的水体), 又存 在大量的光学浅水(遥感反射比受底质影响或者水深不大于光穿透深度的水体). 光学浅水中, 一部分光 穿透水体而到达水底, 然后部分被吸收, 部分又被反射回水体, 或者作为苂光而被重新激发; 因此, 光学 
浅水区水底对遥感反射比有一定的贡献. 光学浅水中, 虽然基本的辐射传输过程没有变化, 但光的传播 环境发生了变化, 从而影响了解决辐射传输问题的假设和边界条件 ${ }^{[1]}$.

Ohde\&Siegel ${ }^{[33]}$ 确定了漫垂直衰减系数与遥感反射比(来自水底和水体)的定量关系, 认为如果(1)式 成立, 则存在底质影响, 否则认为底质对遥感反射的影响很小或者其影响可以忽略; 另外, 只有在 450-650nm 范围内, 才有必要进行湖底反射校正, 否则湖底对遥感反射的贡献可以忽略. 简单的判断: 当 水深大于 2.5 倍衰减距离时 ${ }^{[94]}$ 或者水深大于 3 倍透明度的水体时 ${ }^{[05]}$, 底质的贡献可以忽略.

$$
\ln \left[\frac{R^{\mathrm{b}}-R^{\mathrm{w}}}{R-R^{\mathrm{w}}}\right]=2 K
$$

式中, $R$ 为恰在水面下的辐照度反射比, $R^{\mathrm{b}}$ 为来自水底的恰在水面下的辐照度反射比, $R^{\mathrm{w}}$ 为来自水体的恰 在水面下的辐照度反射比, $K$ 为漫垂直衰减系数.

光学深水中, 对辐射传输有重要影响的物质的性质等已有较深的理解 ${ }^{[96]}$. 在确定的光照条件以及水 面波浪的情况下, 水下光场的变化很大程度上决定于水中的溶解物和悬浮物等光学重要物质, 光强在水 体水平无限的假设条件下, 按照 Beer 定律随深度的增加而减少 ${ }^{[50,97-98]}$, 光学深水的离水辐亮度 $L_{\mathrm{w}}{ }^{\mathrm{w}}$ 与水 深成指数变化关系 ${ }^{[99-101]}$, 其估算误差随着水体深度的减少而增加 ${ }^{[102]}$. 令 $u \equiv b_{\mathrm{b}} /\left(a+b_{\mathrm{b}}\right)$, 有 ${ }^{[103-104]}$ :

$$
R_{\mathrm{rs}}{ }^{\mathrm{w}} \approx g u
$$

式中, $R_{\mathrm{rs}}{ }^{\mathrm{w}}$ 为光学深水遥感反射比. Gordon 等 ${ }^{[104]}$ 通过 Monte Carlo 模拟, 发现对大部分海洋水体而言 有:

$$
R_{\mathrm{rs}}{ }^{\mathrm{w}} \approx(0.0949+0.0794 u) u
$$

Lee 等通过模型计算以及 Hydrolight 模拟对比, 提出了如(5)式, 后来又修正为(5')式 ${ }^{[105]}$ :

$$
\begin{aligned}
& R_{\mathrm{rs}}{ }^{\mathrm{w}} \approx\left(0.070+0.155 u^{0.752}\right) u \\
& R_{\mathrm{rs}}{ }^{\mathrm{w}} \approx(0.084+0.17 u) u
\end{aligned}
$$

对 I 类水体而言, (3)式可以简化为(6)式 ${ }^{[103,106]}$ :

$$
R_{\mathrm{rs}}{ }^{\mathrm{w}} \approx g b_{\mathrm{b}} / a
$$

式中, $g=0.0922$. Lee 等 ${ }^{[107]}$ 通过对比分析认为, (5)式和(6)式的适用条件是 $u<0.3$ 或 $b_{\mathrm{b}} / a<\sim 0.4$; 一般而言, (5)式和(6)式适用于海洋深水, 而(4)式适用于沿岸浑浊水体. $\mathrm{Kirk}^{[98]}$ 认为当 $b_{\mathrm{b}} / a<0.35$ 时, (6)式是有效的; Sathyendranath 等 ${ }^{[108]}$ 和 Lee 等 ${ }^{[109]}$ 认为(6)式的有效的条件分别 $b_{\mathrm{b}} / a \leq 0.3$ 和 $b_{\mathrm{b}} / a<\sim 0.25$; Gordon 等 ${ }^{[110]}$ 、 Morel \& Prieur ${ }^{[106]} 、$ Kirk $^{[98]}$ 以及 Morel \& Gentili ${ }^{[111]}$ 认为对辐照度反射比 $R$ 而言, $g$ 的平均值为 0.33 (假设太 阳处于最高点), 随着太阳天顶角的不同, 会有轻微变化.

针对我国的太湖水体, $\mathrm{Ma}$ 等 ${ }^{[25]}$ 通过实测值与模拟值的分析对比后认为, 最适合的是(3)式, 光学深水 区 $g$ 值的变化范围为 0.0701-0.1064(均值为 0.0924), 其中中浑浊水体 $g$ 值的变化范围为 0.0723-0.1121(均 值为 0.0965), 光学深水区中低无机悬浮物含量水体 $g$ 值的变化范围为 0.0678-0.1006(均值为 0.0882). 因 此, 随着水体的不同, $g$ 值的变化范围很大; 另外还受光照条件(如太阳天顶角)的影响.

对于均质(指无垂直分层)的光学浅水来说, 如果可以忽略非弹性散射的贡献, 有:

$$
R_{\mathrm{rs}}=f\left(a, \beta, A, H, \theta_{w}, \theta_{v}, \varphi\right)
$$

式中, $R_{\mathrm{rs}}$ 是恰在水面以下的遥感反射比 $\left(\mathrm{sr}^{-1}\right), a$ 是总吸收系数 $\left(\mathrm{m}^{-1}\right), a=a_{\mathrm{g}}+a_{\mathrm{p}}+a_{\mathrm{ph}}+a_{\mathrm{w}}$. 其中, $a_{\mathrm{g}}, a_{\mathrm{p}}, a_{\mathrm{ph}}, a_{\mathrm{w}}$ 分 别为 CDOM, 颗粒, 浮游植物色素, 纯水的吸收系数. $\beta$ 是体散射函数 $\left(\mathrm{m}^{-1} \mathrm{sr}^{-1}\right), A$ 是水底反照率 $\left(\mathrm{sr}^{-1}\right), H$ 是水 深 $(\mathrm{m}), \theta_{\mathrm{w}}$ 是恰在水面下的太阳天顶角 $(\mathrm{rad}), \theta_{\mathrm{v}}$ 是恰在水面下的观测角 $(\mathrm{rad}), \varphi$ 是观测方位角 $(\mathrm{rad})$.

在浅水辐射传输的早期大部分工作中，建模模拟的主要方法是统计 ${ }^{[12]}$; 因为计算资源的限制，这些 模拟受到很大的限制; 另外由于没有野外观测仪器, 模型验证无法进行. Ackleson \& Klemas ${ }^{[113]}$ 使用一维 的分析方法解决基于辐照度的传输问题, 但没有进行模型的实际检验. Mobley 等 ${ }^{[114]}$ 报道了一组包含光学 浅水影响模型之间的对比，也没有考虑模型的实际检验，但不同模型的模拟结果是一致的. 后来， Maritorena 等 ${ }^{[115]}$ 报道了一个海洋辐射传输模型实际检验的实例. 这个时期及以后, 由于水下光场测量仪 器的出现, 如德国 Trios 水下光谱仪(RAMSES-ACC-UV/VIS, 波长范围 280-720nm)、美国 ASD 公司 FieldSpec ${ }^{\circledR}$ Pro Dual VNIR 光谱辐射计(波长范围 350-1050nm)佩带的水下镜头和水下全天光余弦接收器, 
内部光场的波谱特征的测量变得可能, 出现了大量关于水体内部光场观测的报道; 所建立的模型的精度 越来越高, 考虑的因素也越来越多.

假设水底是朗伯体, 通过辐射传输方程, 则有 ${ }^{[115]}$ :

$$
R \approx R^{\mathrm{w}}+\left(R^{\mathrm{B}}-R^{\mathrm{w}}\right) \exp (-2 K H)
$$

式中, $R$ 为恰在水面下的辐照度反射比, $R^{\mathrm{B}}$ 为恰在水底以上的辐照度反射比, $K$ 为漫垂直衰减系数 $\left(\mathrm{m}^{-1}\right), R^{\mathrm{w}}$ 和 $H$ 同前. 根据 Lee 等 ${ }^{[107]}$, (8)式可以转化为:

$$
R_{\mathrm{rs}}=R_{\mathrm{rs}}{ }^{\mathrm{w}}[1-\exp (-2 K H)]+\frac{R^{\mathrm{B}}}{\pi} \exp (-2 K H)
$$

Lee 等 ${ }^{[109]}$ 考虑了水体的非弹性过程, 给出了 $R_{\mathrm{rs}}{ }^{\mathrm{b}}$ 的表示式:

$$
R_{\mathrm{rs}}{ }^{\mathrm{b}} \approx 0.17 A \exp \left[-\left(1.5+\left\{D_{d}\right\}\right) \kappa H\right]
$$

式中, $\left\{D_{\mathrm{d}}\right\} \approx 1.08 D_{\mathrm{d}}^{-} \approx 1.08 / \cos \theta_{\mathrm{w}}$, 其中, $D_{\mathrm{d}}{ }^{-}$为恰在水面下的向下分布函数, $\left\{D_{\mathrm{d}}\right\}$ 为垂直平均向下分布函 数; $R_{\mathrm{rs}} \mathrm{b}^{\mathrm{b}}$ 为来自水底的遥感反射比 $\left(\mathrm{sr}^{-1}\right) ; \kappa$ 为准漫衰减系数 $\left(\mathrm{m}^{-1}\right), \kappa=a+b_{\mathrm{b}}$. 后来, 把向上的信号 $S_{\mathrm{u}}$ 明确分解 为来自水体 $S_{\mathrm{u}}{ }^{\mathrm{w}}$ 以及来自水底 $S_{\mathrm{u}}{ }^{\mathrm{b}}$ 等两个部分 ${ }^{[107]}$ :

$$
S_{\mathrm{u}} \equiv S_{\mathrm{u}}{ }^{\mathrm{w}}+S_{\mathrm{u}}{ }^{\mathrm{b}} \approx S_{\mathrm{u}}{ }^{\mathrm{w}}[1-\exp (-2 K H)]+S_{\mathrm{u}}{ }^{\mathrm{B}} \exp (-2 K H)
$$

式中, $S_{\mathrm{u}}$ 表示恰在水面以下的向上辐亮度 $L_{\mathrm{u}}{ }^{-}\left(\mathrm{W} /\left(\mathrm{nm} \cdot \mathrm{m}^{2} \cdot \mathrm{sr}\right)\right.$ 、恰在水面下的辐照度反射比 $(R)$ 或 $R_{\mathrm{rs}}$. 以准单 次散射理论为基础, 在 Hydrolight 的帮助下, Lee 等 ${ }^{[105]}$ 对 Lee 等 $^{[107]}$ 的星下点遥感反射比 $R_{\mathrm{rs}}$ 表达式中的参 数进行了更新, 有:

$$
\begin{aligned}
R_{\mathrm{rs}} \approx R_{\mathrm{rs}}{ }^{\mathrm{w}}(1 & \left.-\exp \left\{-\left[\frac{1}{\cos \left(\theta_{\mathrm{w}}\right)}+1.03(1+2.4 u)^{0.5}\right] \kappa H\right\}\right) \\
+ & \frac{A}{\pi} \exp \left\{-\left[\frac{1}{\cos \left(\theta_{\mathrm{w}}\right)}+1.04(1+5.4 u)^{0.5}\right] \kappa H\right\}
\end{aligned}
$$

式中, $R_{\mathrm{rs}}{ }^{\mathrm{w}}$ 用 $\left(5^{\prime}\right)$ 式表示. Albert \& Mobely ${ }^{[116]}$ 考虑了观测角 $\theta_{v}$ 的影响，给出了更为一般的计算式:

$$
\begin{aligned}
R_{\mathrm{rs}} \approx R_{\mathrm{rs}}{ }^{\mathrm{w}} & \left(1-1.1576 \exp \left\{-\left[1.0546 \frac{\cos \left(\theta_{\mathrm{v}}\right)}{\cos \left(\theta_{\mathrm{w}}\right)}+(1+u)^{3.5421}\left(1-\frac{0.2786}{\cos \left(\theta_{\mathrm{w}}\right)}\right)\right] \frac{\kappa}{\cos \left(\theta_{\mathrm{v}}\right)} H\right\}\right) \\
+ & 1.0389 \frac{R^{\mathrm{B}}}{\pi} \exp \left\{-\left[1.0546 \frac{\cos \left(\theta_{\mathrm{v}}\right)}{\cos \left(\theta_{\mathrm{w}}\right)}+(1+u)^{2.2658}\left(1+\frac{0.0577}{\cos \left(\theta_{\mathrm{w}}\right)}\right)\right] \frac{\kappa}{\cos \left(\theta_{\mathrm{v}}\right)} H\right\}
\end{aligned}
$$

从(8)-(13)式, 是一个逐步求精的过程, 有共同的假设条件即水底是朗伯体, 其基础是水体的辐射传 输过程, 在方程参数化的过程中, Monte Carlo 模拟或 Hydrolight 模拟起了重要作用. 以这些公式为基础, 计算水底底质对遥感反射比的贡献就变得相对容易. 需要注意的是, 不同的水体, 影响因素和影响方式 会有所差别, 另外公式中的参数也有所不同.

国内在基于水体辐射传输的光学浅水底质对遥感反射比的贡献研究方面，尚处于起步阶段. Ma 等 ${ }^{[25]}$ 根据实测塞克盘透明度和水深的关系，把太湖划分为光学深水区和光学浅水区; 在光学浅水区，马荣华 等 ${ }^{[86]}$ 利用 LEE 模型(12)式，通过模拟值与实测值的对比，初步发现太湖草型湖区的底质对恰在水面下遥 感反射比的贡献率在可见光范围内随波长向长波方向的移动呈增加趋势; 在可见光范围内, 底质贡献与 透明度存在较好的一元二次函数关系; 另外，随水生植被的不同生长阶段和空间分布，底质贡献的空间 差异很大. 以此为基础, Ma 等 ${ }^{[117]}$ 通过 Hydrolight 模拟值与实测值以及模型计算值的对比分析发现，光学 浅水区草型底质对遥感反射比的贡献一定程度上取决于水生植被的高度、湖底水深以及水体水质状况; 水底植被越接近水面，对遥感反射比的贡献越大; 一般情况下，当水生植被达到 $80 \%$ 的水深时，遥感反射 比在红光和近红外波段范围内开始表现出类似陆地植被的光谱特征，然而在清澈透底的湖区，当水生植 被达到水深的 $60 \%$ 时, 就会出现类似陆地植被的光谱特征; 另外, 随水生植被高度与水深关系的变化, 底 质对遥感反射比的最大贡献可能出现于 $488 \mathrm{~nm}$ 、 $532 \mathrm{~nm}$ 以及 $589 \mathrm{~nm}$ 等不同波长处.

\section{5 水质参数反演}

凡存在显著光谱特征或光学特性的水体组分参数, 即光活性物质, 都可以通过遥感实施定量反演, 如叶绿素、悬浮物、DOC 等, 被称之为直接水质参数或水色参数, 对湖泊水体中的这些参数实遥感反演, 
称为湖泊水色遥感; 那些不存在显著光谱特征和光学特性(即非光活性物质)、但与直接水质参数存在紧密 内在关联的其他水质参数称之为间接水质参数, 主要包括总氮、总磷以及营养状态指数等, 对这些水体 参数实施遥感反演, 称为水质遥感. 此处我们主要讨论直接水色参数的遥感反演, 即湖泊水色遥感, 反 演方法主要包括经验/半经验方法和分析/半分析方法, 半经验方法的核心是水色参数光谱特征的先验已 知性, 半分析方法的核心是生物光学模型, 各自的优缺点已有较多论述 ${ }^{[6]}$.

目前为止, 大洋 I 类水体水色参数遥感反演的业务化算法仍以半经验方法为主, 典型的如针对 CZCS 和 SeaWiFS 等水色传感器的波段比值算法 ${ }^{[118-119]}$, 实际上针对 MERIS 的神经网络算法也属于半经验算法的 范畴. 国内在近几年认识到湖泊水环境遥感监测的重要性后, 针对不同的湖泊(水库)水体, 如江苏太湖、云 南滇池、安徽巢湖、吉林查干湖、上海淀山湖、湖北三峡水库等, 野外测试获取了大量反射光谱(尤以太湖 的工作最为深人), 掌握了湖泊水体光活性物质的基本光谱特征, 水色参数反演的半经验算法同样占据了主 导地位. 使用半经验方法反演的水色参数除叶绿素和悬浮物外, 还包括 DOC ${ }^{[120]}$ 或 $\mathrm{CDOM}^{[121]}$ 和藻蓝素 (Phycocyanin) $)^{[122]}$, 其中叶绿素的遥感反演是诸多学者关注的重点. 不同的水体, 同一水体在不同的季节, 由于水中物质含量以及组成细胞的差异, 光谱特征波段会有所偏移, 因此虽然特定区域特定时期水色参数 反演的经验/半经验模型在形式上较为稳定, 但模型参数还是存在一定的不确定性, 需要实测数据参与下的 不断率定和校准. 基于实测光谱, 关联水色参数浓度, 可以寻找、发现、分析并掌握水色参数的光谱特征; 基 于卫星遥感影像, 关联水色参数浓度, 可以建立实用的水色参数遥感反演模型, 使用的方法主要包括基于 单波段或波段组合(如比值、差值等)的经验统计回归法 ${ }^{[123]}$ 、神经网络法 ${ }^{[37]}$ 、主成分分析法 ${ }^{[124]}$ 以及遗传算 法 ${ }^{[125]}$ 等, 其中尤以统计回归方法最为常见, 如 SeaWiFS 和 MODIS 叶绿素 a 反演的业务化算法, 但神经网 络法也受到越来越多的重视 ${ }^{[126]}$, 并已成功应用于 MERIS 的水色参数反演中, 成为 MERIS 的业务化算法. 遗憾的是, 目前常用的多光谱传感器波段较宽, 覆盖或淹没了这些水色参数在较窄波段范围内表现出的显 著光谱特征, 原来基于实测光谱所建立的反演模型很难或不能直接用于卫星遥感影像 ${ }^{[1]}$. 虽然基于卫星遥 感影像数据的半经验算法的理论基础不明确, 但在特定的湖区, 针对特定的传感器, 半经验算法却具有较 强的稳定性, 同时具有较高的反演精度, 如在太湖的蓝㩰暴发季节, 对于非蓝藻水华集聚水体, 当叶绿素和

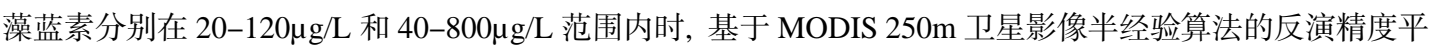
均分别可达 70\%和 $65 \%$. 悬浮物质在红外近红外波段具有更为显著的光谱特征, 基于半经验算法的卫星遥 感反演精度明显高于叶绿素 ${ }^{[123]}$. 目前为止, 湖泊水体 CDOM、DOC 或 DOM 卫星遥感反演的研究还较少, Kuster 等 ${ }^{[121]}$ 利用芬兰南部和瑞典南部 34 个湖泊的实测数据, 基于 ALI 卫星传感器的波段 2(B2)和波段 3(B3) 的比值(B2/B3), 建立了 CDOM 含量(用 $420 \mathrm{~nm}$ 处的吸收来表示)的半经验反演模型(幕指数函数), 表明当 $420 \mathrm{~nm}$ 处 CDOM 吸收在 0.68-11.13m-1 范围内时, ALI 卫星遥感影像可以用来反演 CDOM 含量.

实际上, 湖泊水体光学深水区的光学信号来源于像元内的水体各组分的贡献, 因此可以建立水体混 合光谱分解模型 ${ }^{[10,127]}$. 在已知各组分纯反射光谱的情况下, 得到对应水体组分的分解系数, 然后通过分 解系数与水质参数浓度之间的经验关系模型, 如叶绿素浓度及其分解系数之间的线性或一元二次方程 (15)式 ${ }^{[127]}$, 进而获得水质参数浓度.

目前湖泊水色遥感的研究热点已转移至以生物光学模型为基础的半分析算法. 卫星遥感影像经大气 校正后获取高精度的遥感反射比, 通过生物光学模型, 遥感反射比可表示为后向散射系数与吸收系数的 非线性函数, 而后向散射系数和吸收系数都与水体组分浓度存在紧密的定量关系, 因此通过卫星遥感影 像数据可以反演水体的物质组分浓度. 使用的方法是矩阵分解法 ${ }^{[8,128]}$, 首先利用遥感的正演过程 ${ }^{[1]}$, 建 立水体各组分的吸收系数或比吸收系数与组分浓度之间的定量关系, 根据卫星传感器的波段设置, 假设 固定波段范围内的比吸收系数为定值, 然后根据如(3)式的生物光学模型, 建立相应的矩阵方程组. 一些 文献中讲述的代数法和非线性优化法 ${ }^{[17,89]}$, 本质和核心仍是矩阵分解法.

\section{2 问题与展望}

湖泊水体的污染事件持续时间较短, 水质变化较为迅速, 数小时内就会发生非常大的变化, 如太湖 局部表层水体叶绿素浓度在 $2 \mathrm{~h}$ 左右就会有数倍的差异、甚至发生大面积蓝藻水华集聚(图 1); 其次, 与海 
洋相比, 湖泊面积较小, 我国最大的湖泊青海湖也仅约有 $4500 \mathrm{~km}^{2}$, 水质变化的空间尺度也较小, 往往发 生在数 $10 \mathrm{~m}$ 范围内; 另外, 水体中光活性物质的光谱特征波段较窄, 一般在 $10 \mathrm{~nm}$ 左右 ${ }^{[129-130]}$, 如太湖水 体叶绿素 $685 \mathrm{~nm}$ 附近吸收谷的宽平均约 $7 \mathrm{~nm} 、 700 \mathrm{~nm}$ 附近反射峰的宽平均约 $5 \mathrm{~nm}^{[131]}$, 查干湖的相关研 究也表明了这一点 ${ }^{[132-133]}$. 一般情况下, 多光谱传感器具有较高的空间分辨率, 如 Landsat TM 的空间分 辨率为 30m、CBERS 的空间分辨率为 $19.5 \mathrm{~m}$, 这些传感器的波段设置在宏观上基本能够满足湖泊水体经 验估测叶绿素和悬浮物的需要, 相关研究较多 ${ }^{[13,123,134-137]}$; 遗憾的是, 它们的时间分辨率普遍较低, 不能 满足湖泊水色遥感业务化运行的基本要求; 然而一些适用于海洋水色遥感的卫星传感器, 如 MODIS(空 间分辨率 $250 \mathrm{~m} 、 500 \mathrm{~m}$ 和 $1000 \mathrm{~m}$ ), 由于具有较高的时间分辨率 (1 天 2 次), 特别是 $250 \mathrm{~m}$ 空间分辨率的影 像数据在湖泊水色遥感中得到了重视和广泛应用 ${ }^{[122,124,126,138-142]}$, 并在太湖蓝藻的卫星遥感监测中实现了 业务化运行. 因此对于湖泊水质卫星遥感的业务化运行而言, 首先要求卫星传感器具有高时间分辨率, 其次是高空间分辨率, 然后才是高光谱分辨率. 但通常的极轨卫星传感器很难同时满足上述 3 个要求. 因此, 作为静止卫星的载荷, 综合考虑湖泊水体的空间范围和实际监测要求, 兼顾海洋沿岸水体水质监 测, 研制一个专门的湖泊水色遥感传感器, 将有广阔的应用前景 ${ }^{[1]}$.
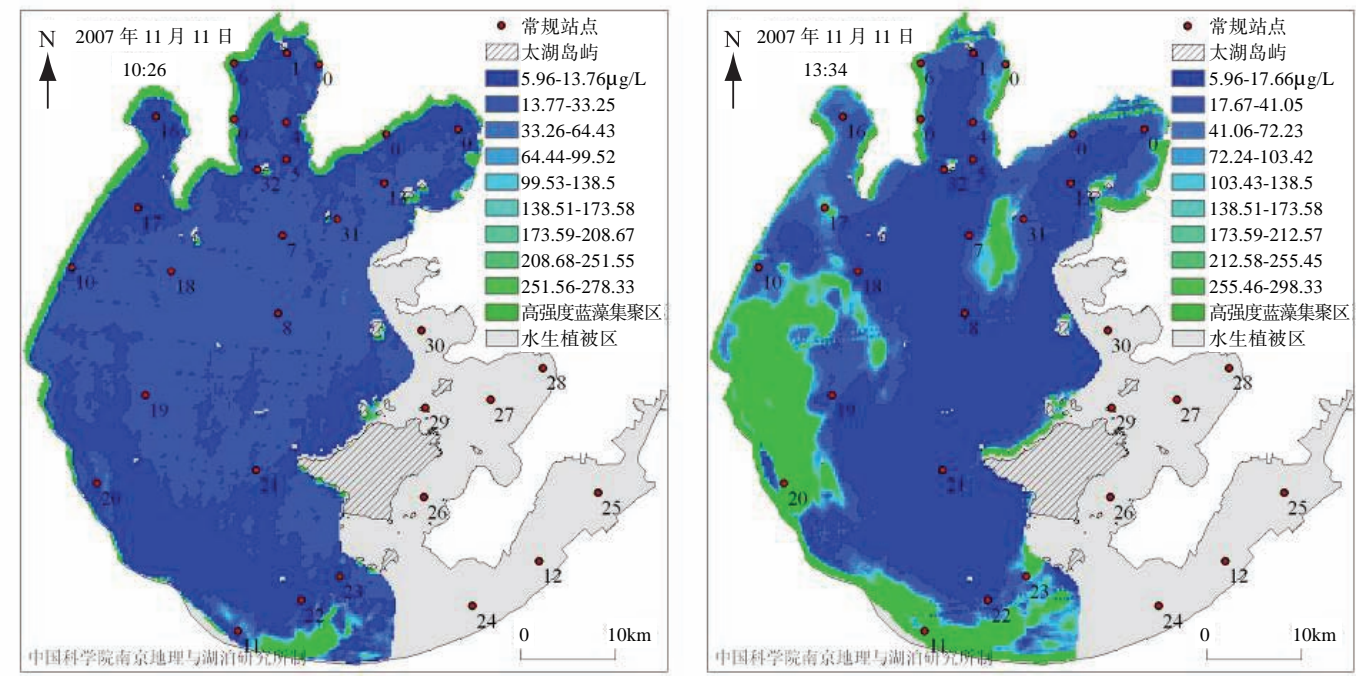

图 12007 年 11 月 11 日 10 时 26 分和 13 时 34 分的太湖水体叶绿素和蓝藻水华空间分布变化 (MODIS 反演结果)

Fig.1 Distributions of Chl.a and algal bloom in Lake Taihu during 10:26 and 13:34, 2007-11-11, respectively

卫星遥感监测水质的另一个优势在于它的长时间序列，通过对比分析，可以发现湖泊水质的长期 变化规律和趋势, 但对遥感定量反演的精度有着严格的要求, 如在 I 类水体叶绿素浓度 SeaWiFS 反演误 差小于 $35 \%$ (相对误差小于 1\%)、离水辐亮度误差小于 $5 \%$ (相对误差小于 $1 \%$ )的情况下, 要求传感器辐射 定标误差小于 $5 \%$ (相对误差小于 $1 \%$ )、波段间的定标误差小于 $5 \%{ }^{[16]}$, 另外要求大气修正算法误差小于 $5 \%{ }^{[21]}$ 、现场测量仪器定标误差小于 $3 \%$ (相对误差小于 $\left.1 \%\right)^{[94]}$ 、现场数据分析处理小于 $5 \%{ }^{[143]}$. 由于湖泊 等 II 类水体更为复杂的光学特性, 水质参数在达到或稍低于 I 类水体同样反演精度的情况下, 对传感器 本身、大气校正算法、现场测量以及反演算法等都提出更高的要求.

(1)陆地辐射校正场在水色传感器中信号一般饱和或接近饱和, 即使不饱和, 产生的信号范围也不在 水色遥感应用的信号范围内, 除非传感器的线性度极高且保持稳定, 因此水色传感器不能依赖陆地定标 场进行辐射定标. 提高定标精度, 有 3 种方法: (1)借助太阳与月亮观测, 提高在轨星上太阳定标和月亮定 标精度; (2)借助其它高性能传感器, 实现不同传感器之间的相对定标和交叉定标; (3)实行替代定标，即 通过卫星数据反演的离水辐亮度值与海面实测值的比较, 系统修正卫星的定标系数, 这个修正实际上包 
括了卫星传感器和业务化大气修正算法的误差和, 也称为 “仪器+算法” 的定标方法. 另外, 充分考虑湖 泊水体光学特性的复杂性以及 3 种物质组分(叶绿素、悬浮物和 CDOM)光谱特征的相互影响, 在恰当的 波谱通道处设置波段, 以实现不同物质组分的探测，如 GLI 在 $380 \mathrm{~nm}$ 处设置通道以探测黄色物质、MERIS 和 GLI 都在 620nm 处设置波段以探测藻蓝素含量, MODIS、MERIS 和 GLI 均在 680nm 处设置波段以探 测叶绿素含量. 近期的研究表明 ${ }^{[22-43]}$, 短波近红外大气校正算法非常适合于湖泊等 II 类水体, 但对气溶 胶模型误差非常敏感, 需要紫光波段离水辐亮度的反演来限制气溶胶模型误差. 因此新型传感器应该在 蓝紫光(440nm 以下)以及短波近红外(1600-2500nm)波段范围内设置用于大气校正的波段; 高光谱传感器 虽然可以满足这一要求, 但需要提高信噪比, 至少达到或接近 SeaWiFS 的信噪比水平(SNR > 400), 另外还 需降低或剔除波段间的相互干扰.

(2)高精度的生物光学模型是水色参数反演的基础和依据, 准确表述固有光学量和表观光学量之间的 定量关系, 需要系统地了解这些水体颗粒物(包括无机和有机)的物理特性(大小、粒径、折射指数等), 发 展湖泊水体固有光学量和表观光学量的精确测量技术. (1)目前流行的两种测量后向散射的仪器 HS-6 和 BB-9 在太湖的试验结果相差较大, 一方面是由于水体本身的差异造成的, 另一方面也来自于仪器的系统 误差; 因此提高仪器的测量精度, 实现不同仪器之间的相对定标, 确定不同水体的后向散射概率, 是提 高后向散射系统测量精度的重要步骤. 另外, 在系统了解并掌握水体中各种矿物质以及各种藻种的折射 指数和粒子谱分布的基础上, 基于米散射理论, 借助相关参数的现场测量(如吸收系数、衰减系数), 建立 后向散射系数的闭合试验，对精确获取后向散射系数非常重要; (2)在 NASA SeaWiFS 测量标准的基础上， 考虑到湖泊水体中无机悬浮颗粒比重较高、颗粒粒径不一、过滤后滤膜上分布不均等特点，建立一套适 合湖泊水体的过滤、萃取等试验过程以及散射校正等后处理过程的光活性物质吸收系数的高精度测量技 术，是实验室精确获取水体中光活性物质吸收的关键; (3)目前为止，还没有能够适用于 $2 \mathrm{~m}$ 以浅的剖面测 量仪器, 大家通用的德国 TRIOS 水下光谱仪, 由于体积大、剖面测量不同步等原因, 会造成测量值和计 算值之间大的误差, 剖面法不适合像太湖这样的浅水湖泊, 因此水面以上法受到了极大的重视, 并获得 了广泛应用; 然而需要注意的是, 除了测量过程中的不确定性影响外(如船体的晃动/移动、水体及其底质 的摚动、泡沫等), 我们常用的光谱仪的光谱范围为 350-1050nm(如美国 ASD 公司的双通道地物波谱仪 FieldSpec 931), 考虑到水体的浑浊度及其大气校正算法研究的需要, 这个光谱范围显得不够, 在保持 双通道测量的前提下, 扩展到 $2500 \mathrm{~nm}$ 即 350-2500nm 是最好的选择; (4)光学浅水中, 底质对遥感反射 比有一定的贡献 ${ }^{[96]}$, 建立基于水体辐射传输的底质贡献模型, 需要底质的光谱反射特性, 假设是硬质 湖底, 可以通过水下光谱仪或者普通的地物光谱仪携带的水下镜头来测量, 假设是底泥, 直接在湖体 中测量的难度就较大, 如何测量? 可以把底泥采集上来, 放置于单独的容器中, 是干燥后测量? 还是湿 中带水测量?或者表面带有一层薄水层的情况下测量? 哪一种测量方法更具有代表性, 可以更加真实的逼 近真值?另外, 目前的研究都是基于朗伯性水底的假设而进行的, 实际上它是一个 BRDF 函数, 问题在于 如何测量水下底质的 BRDF; (5)早期在做星地同步试验时，在没有外因环境影响的条件下，同卫星过境 时刻相比，我们通常认为上午和下午、甚至前一天和后一天是准同步的或实时的; 然而，近 2 年来的太湖 水色遥感研究表明, 这与实际情况存在较大偏差、甚至错误; 因此对于像太湖这种水质变化迅速的水体, 如何保证星地试验的同步性以及野外现场试验的可比性, 是一个非常值得思考的问题; 否则, 会给我们 的遥感反演模型带来不可预知的误差甚至错误. (6)为了获取系统的、适用的水色遥感试验数据, 可考虑 建立固定的湖泊水色遥感试验平台, 真正实现星地同步观测, 减少建模误差, 提高反演精度.

(3)基于卫星遥感反演，对湖泊水质进行长时间序列的分析和对比，需要解决好几个基础的共性关键 问题: (1)首先是大气校正, 需要针对内陆湖泊水体的特点, 改进基于严格气溶胶校正的适用于大洋开阔 水体的 Gordon 大气校正方法, 发展非 Gordon 大气校正方法或不需要严格计算气溶胶的隐含大气校正的 水色反演算法; 另外, 可针对区域高浑浊水体的特点, 借鉴陆地遥感的大气校正方法, 如基于图像自身 的大气校正，包括暗目标法 ${ }^{[144-145]}$ 、内在平均相对反射率模型法 ${ }^{[146]}$ 以及平面场模型法 ${ }^{[147]}$, 或者基于实测 光谱的大气校正方法, 即以地面目标的反射率与遥感器探测的信号之间具有线性关系为假设条件, 首先 实地测量湖区内浑浊水体的反射光谱, 然后获取影像上对应水体的灰度值, 最后建立二者之间的线性回 
归方程，以此对整幅影像进行校正; (2)除纯水外, 水体的总吸收还包括浮游植物色素的吸收、黄色物质的 吸收和无机悬浮颗粒的吸收, 其中纯水的吸收是确定的、已知的, 浮游植物色素的吸收有着显著的特征, 而黄色物质的吸收和无机悬浮颗粒的吸收非常相似，甚至高度接近，如何从总的吸收光谱中实现二者的 有效分离?以高精度地获取对应的物质组份含量, 需要从数学建模的角度人手加以解决; 3湖泊水体中一 般含有大量悬浮物质，从而产生较强的后向散射和水体反射信号，同其相比，叶绿素信号明显偏弱，因 此会被强的悬浮物质信号掩盖或淹没, 进而造成遥感反演中叶绿素信号失真, 影响遥感反演精度, 因此 对湖泊水体而言, 在叶绿素遥感反演的过程中, 如何剔除悬浮物质的影响? 一方面需要二者及其水环境 光学特性的基础知识, 另一方面需要加强数学建模研究; (4)湖泊水体的光学特性复杂, 3 种主要光活性物 质的吸收和后向散射光谱相互影响, 而在目前生物光学特性的定量模型中, 都以线性关系来描述, 势必 造成三者物质含量的反演误差, 如何建立三者更为真实的关系模型?影响着基于生物光学模型的反演精 度; (5)如(3)式的生物光学模型中, 在不同的湖泊, 同一湖泊不同的季节, 甚至同一湖泊不同的湖区，随固 有光学量特别是颗粒散射函数的不同 ${ }^{[148]}, g$ 值有所变化, 另外还受到太阳高度角的影响, 因此如何建立 一个统一的模式, 高精度地定量化 $g$ 值，也是一个需要重点关注的问题; 另外，为了高精度的计算或模拟 湖泊浑浊水体的遥感反射比, Gordon 等 ${ }^{[18,110]}$ 的类似幂级数的辐射传输反演模型需要保留到哪一项? 即如 (3)式的模型公式中是否还需要添加方程的二次项、三次项?如何保证遥感反射比与固有光学量的闭合关 系？都是一个值得讨论的问题，也影响着基于生物光学模型的反演精度.

(4)目前水色遥感界普遍认为 ${ }^{[135,149]}$, 由于模型参数的差异, 很难建立一种普适的水色遥感反演模式. 不同的湖泊水体、同一湖泊不同的湖区、同一湖区不同的季相, 水体物质组分的空间差异都很大, 引起 固有光学特性大的空间分异, 生物光学模型参数具有很大的区域性, 不能统一参数化. 对湖泊水体而言, 基于生物光学模型的半分析算法很难业务化运行, 除湖泊水体大的空间分异外, 另一个大的障碍来自卫 星传感器, 目前在轨的卫星传感器在满足湖泊水色遥感时间分辨率和空间分辨率的同时, 很难有足够的 光谱分辨率支持半分析算法的模型求解; 基于光谱特征分析的半经验算法针对不同的水体尤其需要建立 不同的区域化模型, 不能以一个统一的模型实现整个水体的水色参数反演. 因此目前需要针对我们关心 的区域水体，以半经验算法模式为基础，取得深人认识后，再进行半分析算法，如果能够建立隐含大气 校正的一体化水色反演算法, 将为湖泊水色遥感的业务化奠定坚实的基础.

(5)野外采样点尺度非常小, 对应的遥感分析与参数反演发生在图像像元的尺度上, 对 MODIS 而言, 这种像元尺度是 $250 \mathrm{~m} 、 500 \mathrm{~m}$ 或 $1000 \mathrm{~m}$, 即使 Landsat TM 而言, 这种像元尺度也有 $30 \mathrm{~m}$, 而湖泊水体水 质的空间差异很大, 发生这种较大差异的空间尺度很小, 有时仅发生在数米的距离范围内, 因此存在采 样点尺度与遥感像元尺度不匹配的问题; 另外，不同空间分辨率的卫星遥感影像，像元具有不同的尺度 结构及模型表达, 在利用这些影像数据反演水质参数时, 虽然使用了同时同地的野外采样点数据, 所产 生的水质参数遥感反演产品也存在一定的尺度差别, 因此存在不同卫星遥感影像像元尺度的匹配与转换 问题、基于不同卫星遥感影像的反演产品的尺度匹配与数据产品同化问题. 可见, 尺度问题显著地贯穿 于水质参数遥感反演过程的始终. 建立水质参数遥感反演的尺度模型, 可以更加准确地定量卫星遥感的 反演误差、理解误差的传递过程及其尺度误差对反演结果的影响和贡献.

(6)湖泊水色遥感的反演精度一方面取决于大气辐射传输和水体辐射传输过程的建模精度, 另一方面 也受制于水体的动力学过程, 特别是浅水型湖泊, 在外力如风的作用下, 不断摚动, 而卫星遥感反演建 模总是基于某一时刻或某一时间段的现场采样，同建模时刻或时段的水环境相比，反演运行过程中面对 的水环境发生了较大变化, 势必带来较大的反演误差. 融合水动力过程, 建立综合一体化的卫星遥感反 演模型, 不但可以提高水色参数的反演精度, 而且可以为湖泊水质的预测预警提供基础和依据.

进步与挑战共存. 湖泊水体物质组份的复杂性以及卫星传感器与实际需求的矛盾决定了问题解决的 难度, 湖泊水色遥感在一些关键问题上仍没有实质性进步, 离水质监测的业务化尚有一段距离. 令人欣 慰的是, 卫星传感器以及水色遥感反演算法的不断发展和进步, 让我们看到了胜利的曙光.

致谢: 美国密西西比州立大学李忠平教授对本文的修改提出了宝贵的意见和建议, 谨此致谢. 


\section{3 参考文献}

[1]＼cjkstart潘德炉，马荣华. 湖泊水质遥感的几个关键问题. 湖泊科学, 2008, 20(2): 139-144.

[2] Jin ZH, Stamnes K. Radiative transfer in nonuniformly refracting layered media: Atmosphere-ocean system. Appl Opt, 1994, 33: 431-442.

[3] Frank F, Fischer J. Numerical simulation of the light field in the atmosphere-ocean system using the matrix-operator method. $J$ Quant Spect Rad Trans, 2001, 69: 351-388.

[4] Chami M, Santer R, Dilligeard E. Radiative transfer model for the computation of radiance and polarization in an ocean-atmosphere system: polarization properties of suspended matter for remote sensing. Appl Opt, 2001, 40: 2398-2416.

[5] 何贤强, 潘德炉, 朱乾坤等. 基于矩阵算法的海洋一大气耦合矢量辐射传输数值计算. 中国科学, 2006, 36(9): 860-870.

[6] 马荣华, 唐军武. 湖泊水色遥感参数获取与算法分析. 水科学进展, 2006, 17(5): 720-726.

[7] 马 毅, 张 杰. 二类水体水色要素高光谱遥感. 海洋监测高技术 2003 年度战略研讨会, 2003.

[8] Brando VE, Dekker AG. Satellite hyperspectral remote sensing for estimating estuarine and coastal water quality. IEEE Transactions on Geoscience and Remote Sensing, 2003, 41: 1378-1387.

[9] 闻见光, 肖 青, 杨一鹏等. 基于 Hyperion 数据的太湖水体叶绿素 a 浓度遥感估算. 湖泊科学, 2006, 18(4): 327-336.

[10] 肖 青, 闻建光, 柳钦火等. 混合光谱分解模型提取水体叶绿素含量的研究. 遥感学报, 2006, 10(4): 559-567.

[11] Hoogenboom HJ, Dekker AG, Althuis A. Simulation of AVIRIS sensitivity for detecting chlorophyll over coastal and inland waters. Remote Sensing of Environment, 1998, 65: 333-340.

[12] 匡定波, 沈鸣明, 汪骏发等. 航空成像光谱水质遥感研究. 红外与毫米波学报, 2000, (4): 252-256.

[13] Östlund C, Flink P, Strömbeck N et al. Mapping of the water quality of Lake Erken, Sweden, from Imaging Spectrometry and Landsat Thematic Mapper. The Science of the Total Environment, 2001, 268: 139-154.

[14] 王迪峰, 潘德炉, 龚 芳等. 高光谱成像仪 AISA+应用试验. 仪器仪表学报, 2006, 27(2): 1167-1169.

[15] Kirk JTO. Light and photosynthesis in aquatic ecosystems. Cambridge: Cambridge University Press, 1994.

[16] Hooker SB, Esaias WE, Feldman GC et al. SeaWiFS Technical Report Series, Volume 1, An overview of SeaWiFS and Ocean Color. NASA Technical Memorandum, 104566, 1992.

[17] 任敬萍, 赵进平. 二类水体水色遥感的主要进展与发展前景. 地球科学进展, 2002, 17(3): 363-371.

[18] Gordon HR, Brown OB, Evans RH et al. A semianalytic radiance model of ocean color. Journal of Geophysical Research, 1988, 93: $10909-10924$

[19] Wang M. Atmospheric correction of the second generation ocean color sensors. PH.D dissertation. University of Miami, 1991.

[20] Gordon HR, Wang M. Surface-roughness considerations for atmospheric correction of ocean colour sensors. Appl Opt, 1992, 31(21): 4266-4274.

[21] Gordon HR, Wang M. Retrieval of water-leaving radiance and aerosol optical thickness over the oceans with SeaWiFS: a preliminary algorithm. Appl Opt, 1994, 33(3): 443-452.

[22] Sturm B. CZCS data processing algorithms. Ocean Colour: Theory and applications in a decade of CZCS experience. Netherlands: Kluwer Academic Publishers, 1993: 95-115.

[23] 赵 崴, 林明森, 陈光明等. “HY-1”卫星 COCTS 水色遥感精确瑞利散射算法研究. 海洋学报, 2006, 28(3): 139-143.

[24] 孙 凌, 张 杰, 郭茂华. 针对 HY-1A CCD 数据处理的瑞利查找表. 遥感学报, 2006, 10(3): 306-311.

[25] Ma R, Tang J, Dai J. Bio-optical model with optimal parameter suitable for Taihu Lake in water colour remote sensing. International Journal of Remote Sensing, 2006, 27: 4303-4326.

[26] Gallegos CL, Neale PJ. Partitioning spectral absorption in case 2 waters: discrimination of dissolved and particulate components. Appl Opt, 2002, 41(21): 4220-4233.

[27] 元雪勇, 田庆久. 光学遥感大气校正研究进展. 国土资源遥感, 2005, (4): 1-6.

[28] Arnone RA, Martinolich P, Gould RW et al. Coastal optical properties using SeaWiFS. SPIE Ocean Optics XIV, 1998: $304-312$.

[29] Hu C, Carder KL, Muller-Karger FE. Atmospheric correction of SeaWiFS imagery over turbid coastal waters: a practical method. Remote Sensing of Environment, 2000, 74: 195-206.

[30] Ruddick KG, Ovidio F, Rijkeboer M. Atmospheric correction of SeaWiFS imagery for turbid coastal and inland waters. Appl Opt, 2000, 39: 897-912. 
[31] 韦 钧, 陈楚群, 施 平. 一种实用的二类水体 SeaWiFS 资料大气校正方法. 海洋学报, 2002, 24(4): 118-126.

[32] 李 花. 二类水体大气校正方法研究及其在水色信息提取中的影响[硕士论文]. 广州: 中山大学, 2006.

[33] Doerffer R, Schiller H. Determination of case 2 water constituents using radiative transfer simulation and its inversion by neural network. In: Ackleson SG ed. Proceedings of Ocean Optics XIV Conference, Hawaii, November 10-13, 1998.

[34] Schiller H, Doerffer R. Neural network for emulation of an inverse model-operational derivation of case II water properties from MERIS data. International Journal of Remote Sensing, 1999, 20(9): 1735-1746.

[35] 詹海刚, 施 平, 陈楚群. 利用神经网络反演海水叶绿素浓度. 科学通报, 2000, 45(17): 1879-1884.

[36] Zhang Y, Pulliainen J, Koponen S et al. Application of an empirical neural network to surface water quality estimation in the Gulf of Finland using combined optical data and microwave data. Remote Sensing of Environment, 2002, 81: 327-336.

[37] 丁 静. 基于神经网络的二类水体大气修正与水色要素反演[博士论文]. 青岛: 中国海洋大学, 2004.

[38] Neumann A, Krawczyk H, Walzel T. A complex approach to quantitative interpretation of spectral high resolution imagery. Proceedings of the Third Thematic Conference on Remote Sensing for Marine and Coastal Environments, Seattle, Sept, 1995: II641-652.

[39] Neumann A, Krawczyk H. Principal component inversion. From Training course on remote sensing of ocean color. Ahmedabad, India, 2001.

[40] 丁 静, 唐军武, 宋庆君等. 中国近岸混浊水体大气修正的迭代与优化算法. 遥感学报, 2006, 10(5): 732-741.

[41] He X, Pan D, Mao Z. Atmospheric correction of SeaWiFS imagery for turbid coastal and inland waters. Acta Oceanologica Sinica, 2004, 23(4): 609-615.

[42] Wang M. Remote sensing of the ocean contributions from ultraviolet to near-infrared using the shortwave infrared bands: simulations. Appl Opt, 2007, 46: 1535-1547.

[43] Oo M, Vargas M, Gilerson A et al. Ahmed S. Improving atmospheric correction for highly productive coastal waters using the short wave infrared retrieval algorithm with water-leaving reflectance constraints at 412nm. Appl Opt, 2008, 47: 3846-3859.

[44] Strömbeck N. Water quality and optical properties of Swedish lakes and coastal waters in relation to remote sensing. Comprehensive Summaries of Uppsala Dissertations from the Faculty of Science and Technology 663. Acta Universitatis Upsaliensis, Uppsala, 2001.

[45] Ma R, Tang J, Dai J et al. Absorption and scattering properties of water body in Taihu Lake, China: absorption. International Journal of Remote Sensing, 2006, 27(19): 4277-4304.

[46] 汪小勇, 李铜基. 双通道高光谱地物波谱仪测量水体的遥感反射率. 海洋技术, 2003, 22(3): 20-24.

[47] Mueller JL, Fargion GS, McClain CR. Ocean optics protocols for satellite ocean color sensor validation, Revision 4, Volume 1-5, Greenbelt, Maryland, 2003.

[48] 唐军武, 田国良, 汪小勇等. 水体光谱测量与分析 I: 水面以上法. 遥感学报, 2004, 8(1): 37-44.

[49]＼cjkstart李＼cjkstart刚. 水体吸收衰减系数测量仪定标技术. 海洋技术, 2005, 24(4): 120-123.

[50] Jerlov NG. Marine Optics. Amsterdam: Elsevier, 1976.

[51] Smith RC, Baker KS. Optical properties of the clearest natural waters (200-800nm). Appl Opt, 1981, 20(2): 177-184.

[52] Sogandares FM, Fry ES. Absorption spectrum (340-640nm) of pure water. II. Photothermal measurements. Appl Opt, 1997, 36(33): 8699-8709.

[53] Pope RM, Fry ES. Absorption spectrum (380-700nm) of pure water. II . Integrating cavity measurements. Appl Opt, 1997, 36: 8710-8722

[54] 曹文熙, 杨跃忠, 许晓强等. 珠江口悬浮颗粒物的吸收光谱及其区域模式. 科学通报, 2003, 48(17): 1876-1882.

[55] Balch WM, Holligan, PM, Ackleson SG et al. Biological and optical properties of mesoscale coccolithophore blooms in the Gulf of Maine. Limnology and Oceanography, 1991, 36: 629-643.

[56] Lee ME, Lewis MR. A new method for the measurement of the optical volume scattering function in the upper ocean. Journal of Atmospheric and Oceanic Technology, 2003, 20: 563-571.

[57] 宋庆君, 唐军武, 马荣华. 水体后向散射系数校正方法研究. 海洋技术, 2008, (1): 48-52.

[58] HOBI-labs Inc. Backscattering Sensor Calibration manual (Revision J). http://www.hobilabs.com (accessed 24 July 2003).

[59] Kirk JTO. Estimation of the scattering coefficient of natural waters using underwater irradiance measurements. Australian Journal of Marine and Freshwater Research, 1981, 32: 533-539. 
[60] Whitlock CH, Pool LR, Usry JW et al. Comparison of reflectance with backscatter and absorption parameters for turbid waters. Appl Opt, 1981, 20: 517-522.

[61] Aas E, Høkedal J, Sørensen K. Spectral backscattering coefficient in coastal waters. International Journal of Remote Sensing, 2005, 26: 331-343.

[62] 马荣华, 宋庆君, 李国砚等. 太湖水体的后向散射概率. 湖泊科学, 2008, 20(3): 375-379.

[63] Ma R, Pan D, Duan H et al. Absorption and scattering properties of water body in Taihu Lake, China: Backscattering. International Journal of Remote Sensing, 2008 (In press).

[64] 李俊生, 张 兵, 张 霞等. 一种计算水体中悬浮物后向散射系数的方法. 遥感学报, 2008, 12(2).

[65] 陈清莲, 唐军武, 王项南等. 东海实验区水体光谱特性现场测量与数据分析. 海洋技术, 1999, 18(3): 25-37.

[66] 唐军武, 陈清莲, 谭世祥等. 海洋光谱测量与数据分析处理方法. 海洋通报, 1998, 17(1): 71-79.

[67] 李铜基, 陈清莲, 朱建华. 我国近岸 II 类海水光谱特性的测量与研究. 海洋通报, 2002, 21(6): 9-15.

[68] 汪小勇, 李铜基, 杨安安. 黄东海海区表观光学特性和固有光学特性春季模式研究. 海洋技术, 2004, 23(4).

[69] 唐军武, 王晓梅, 宋庆君等. 黄、东海二类水体水色要素的统计反演模式. 海洋科学进展, 2004, 22(1).

[70] 赵冬至, 罗 虎, 傅云娜. 海洋水色组分吸收系数的测定方法研究. 海洋通报, 2004, 23(3): 81-86.

[71] 潘德炉, 王迪峰. 我国海洋光学遥感应用科学研究的新进展. 地球科学进展, 2004, 19(4): 506-512.

[72] 王晓梅, 唐军武, 宋庆君等. 黄海, 东海水体总吸收系数光谱特性及其统计反演模式研究. 海洋与湖沼, 2006, 37(3).

[73] 宋庆君, 唐军武. 黄海、东海海区水体散射特性研究. 海洋学报, 2006, 28(4): 56-63.

[74] Balkanov V, Belolaptikov I, Bezrukov L et al. Simultaneous measurements of water optical properties by AC9 transmissometer and ASP-15 inherent optical properties meter in Lake Baikal. Nuclear Instruments and Methods in Physics Research, 2003, 498: 231-239.

[75] La A, Giordano P, Barbini R et al. Bio-optical investigation on the Albano Lake. In Proceedings of EARSeL-SIG-Workshop LIDAR, 16-17 June 2000, Dresden, FRG, 2000: 185-195.

[76] Kallio K. Absorption property of dissolved organic matter in Finnish lakes. Proc Estonian Acad Sci Biol Ecol, 1999 , 48: 75-83.

[77] Reinart A. Underwater light field characteristics in different types of Estonian and Finnish lakes[PhD Thesis]. Estohia: University of Tartu, 2000.

[78] Gallie EA, Murtha PA. Specific absorption and backscattering spectra for suspended minerals and chlorophyll-a in Chilko Lake, British Columbia. Remote Sensing of Environment, 1992, 39: 103-118.

[79] Bukata RP, Jerome JH, Kondratyev KY et al. Estimation of organic and inorganic matter in inland waters: optical cross sections of Lakes Ontario and Ladoga. Journal of Great Lakes Research, 1991, 17: 461-469.

[80] 张运林, 黄群芳, 马荣华等. 基于反射率的太湖典型草藻型湖区溶解性有机碳的反演. 地球科学进展, 2005, 20(7): $772-777$.

[81] 张运林, 秦伯强, 马荣华等. 太湖典型草藻型湖区有色可溶性有机物的吸收与苂光特性. 环境科学, 2005, 26(2): 142-147.

[82] 张运林, 吴生才, 秦伯强等. 太湖梅梁湾有色可溶性有机物对光的吸收. 中国环境科学, 2004, 24(4): 405-413.

[83] 马荣华, 戴锦芳, 张运林. 东太湖 CDOM 吸收光谱的影响因素与参数确定. 湖泊科学, 2005, 17(2): 120-126.

[84] 马荣华, 宋庆君, 唐军武等. 太湖秋季水体遥感反射比的简单经验估测模型. 湖泊科学, 2007, 19(3): $227-234$.

[85] 马荣华, 段洪涛, 张寿选等. 太湖草型湖区底质对遥感反射比的贡献. 遥感学报, 2008, 12(3): 483-489.

[86] 孙德勇, 李云梅, 王 桥等. 太湖水体散射特性及其空间分异. 湖泊科学, 2008, 20(3): 389-395.

[87] 乐成峰, 李云梅, 查 勇等. 太湖梅梁湾水体组分吸收特性季节差异分析. 环境科学, 2008, 29(9): 2448-2455.

[88] 周冠华, 柳钦火，马荣华等. 基于半分析模型的波段最优化组合反演混浊太湖水体叶绿素 a. 湖泊科学, 2008, 20(2): 153-159.

[89] 张 兵, 申 茜, 李俊生等. 太湖水体 3 种典型水质参数的高光谱遥感反演. 湖泊科学, 2009, 21(2): 182-192.

[90] 周虹丽, 朱建华, 李铜基等. 青海湖水色要素吸收光谱特性分析一一黄色物质、非色素颗粒和浮游植物色素. 海洋技术, 2005, 24(2): 55-58.

[91] 汪小勇, 李铜基, 朱建华. 青海湖水表光学特性分析. 海洋技术, 2005, 24(2): 50-54.

[92] 李 方, 徐京萍, 何艳芬等. 长春市石头口门水库颗粒物光谱吸收特性. 湖泊科学, 2009, 21(2): 280-287.

[93] Ohde T, Siegel H. Correction of bottom influence in ocean colour satellite images of shallow water areas of the Baltic Sea. International Journal of Remote Sensing, 2001, 22: 297-313.

[94] Mueller JF, Austin RW. Ocean optics protocols for SeaWIFS validation (V1). Maryland: Goddard Space Flight Center, 1995.

[95] Lodhi MA, Rundquist DC. A spectral analysis of bottom-induced variation in the colour of Sand Hills lakes, Nebraska, USA 
International Journal of Remote Sensing, 2001, 22: 1665-1682.

[96] Ackleson SG. Light in shallow waters: A brief research review. Limnology \& Oceanography, 2003, 48: 323-328.

[97] Mobley CD. Light in water. Academic Press, 1994.

[98] Kirk JTO. Dependence of relationship between inherent and apparent optical properties of water on solar altitude. Limnology and Oceanography, 1984, 29: 350-356.

[99] Lyzenga DR. Passive remote sensing techniques of mapping water depth and bottom features. Appl Opt, 1978, 17 : 379.

[100] Lyzenga DR. Remote sensing of bottom reflectance and water attenuation parameters in shallow water using aircraft and Landsat data. International Journal of Remote Sensing, 1981, 2: 71.

[101] Lyzenga DR. Shallow-water bathymetry using combined lidar and passive multispectral scanner data. International Journal of Remote Sensing, 1985, 6: 697.

[102] Tassan S. A procedure to determine the particular content of shallow water from Thematic Mapper data. International Journal of Remote Sensing, 1998, 19: 557-562.

[103] Morel A, Gentili B. Diffuse reflectance of oceanic waters: II . Bidirectional aspects. Appl Opt, 1993, 32: 6864-6879.

[104] Grodon HR, Brown OB, Evans RH et al. A semianalytic radiance model of ocean color. Journal of Geophysical Research, 1988, 93(D9): 10909-10924.

[105] Lee Z, Carder KL, Mobley CD et al. Hyperspectral remote sensing for shallow waters: 2. Deriving bottom depths and water properties by optimization. Appl Opt, 1999, 38: 3831-3843.

[106] Morel A, Prieur L. Analysis of variations in ocean color. Limnology \& Oceanography, 1977, 22: 709-722.

[107] Lee Z, Carder KL, Mobley CD et al. Hyperspectral remote sensing for shallow waters: 1. A semianalytical model. Appl Opt, 1998, 37: 6329-6338.

[108] Sathyendranath S, Prieur L, Morel A. A three-component model of ocean colour and its application to remote sensing of phytoplankton pigments incoastal waters. International Journal of Remote Sensing, 1989, 10: 1373-1394.

[109] Lee Z, Carder KL, Hawes SK et al. Model for the interpretation of hyperspectral remote-sensing reflectance. Appl Opt, 1994, 33: 5721-5732.

[110] Gordon HR, Brown OB, Jacobs MM. Computed relationship between the inherent and apparent optical properties of a flat homogeneous ocean. Appl Opt, 1975, 14: 417-427.

[111] Morel A, Gentili B. Diffuse reflectance of oceanic waters: its dependence on sun angle as influenced by the molecular scattering contribution. Appl Opt, 1991, 30: 4427-4438.

[112] Gordon HR, Brown OB. Influence of bottom depth and albedo on the diffuse reflectance of a flat homogeneous ocean. Appl Opt, 1974, 13: 2153-2159.

[113] Ackleson SG, Klemas V. Two-flow simulation of the natural light field within a canopy of submerged aquatic plants. Appl Opt, 1986, 25: 1129-1136.

[114] Mobley CD, Gentili B, Gordon HR et al. Comparison of numerical models for computing underwater light fields. Appl Opt, 1993, 32: 7484-7504.

[115] Maritorena S, Morel A, Gentili B. Diffuse reflectance of oceanic shallow waters: influence of water depth and bottom albedo. Limnology \& Oceanography, 1994, 39: 1689-1703.

[116] Albert A, Mobely CD. An analytical model for subsurface irradiance and remote sensing in deep and shallow case-2 waters. Optics Express, 2003, 11: 2873-2890.

[117] Ma R, Duan H, Liu Q. Approximate bottom contribution to remote sensing reflectance in Taihu Lake, China. IEEE Transactions on Geoscience and Remote Sensing, 2008 (In review)

[118] Clark DK. Phytoplankton pigment algorithms for the Nimbus-7 CZCS. In: Gower JFR ed. Oceanography from Space. New York: Plenum Press Inc, 1981: 227-238

[119] Aiken J, Moore GF, Trees CC et al. The SeaWiFS CZCS-type pigment algorithm. NASA Technical Memorandum 104566, SeaWiFS Technical Report Series, Vol. 29, NASA, Greenbelt, MD, USA, 1995.

[120] 陈楚群, 施 平. 应用水色卫星遥感技术估算珠江口海域溶解有机碳浓度. 环境科学学报, 2001, 21(6): 715-719.

[121] Kutser T, Pierson DC, Kallio KY et al. Mapping lake CDOM by satellite remote sensing. Remote Sensing of Environment, 2005, 
94: $535-540$.

[122] 马荣华, 孔维娟, 段洪涛等. 利用 MODIS 影像估测太湖蓝藻暴发期的藻蓝素含量. 中国环境科学, 2008(接受).

[123] 马荣华, 戴锦芳. Landsat ETM 与光谱特征结合估测太湖叶绿素及悬浮质含量. 湖泊科学, 2005, 17(2): 97-103.

[124] 王艳红, 郑正栋, 马荣华. 基于实测光谱与 MODIS 数据的太湖悬浮物定量估测. 环境科学学报, 2007, 27(3): 509-515.

[125] 詹海刚, 施 平, 陈楚群. 基于遗传算法的二类水体水色遥感反演. 遥感学报, 2004, (1).

[126] 孔维娟, 马荣华, 段洪涛. 结合温度因子估算太湖叶绿素 a 含量的神经网络模型. 湖泊科学, 2009, 21(2): 193-198.

[127] Oyama Y, Matsushita B, Fukushima T et al. A new algorithm for estimating chlorophyll-a concentration from multi-spectral satellite data in case II waters: a simulation based on a controlled laboratory experiment. International Journal of Remote Sensing, 2007, 28: 1437-1453.

[128] 唐军武, 田国良. 水色光谱分析与多成分反演算法. 遥感学报, 1997, 1(4): 252-256.

[129] Gitelson A. The peak near 700nm on radiance spectra of algae and water: relationship of its magnitude and position with chlorophyll concentration. International Journal of Remote Sensing, 1992, 13: 3367-3373.

[130] IOCCG. Minimum requirements for an operational ocean color sensor for the open ocean. IOCCG Project Office, Report No.1, 1998: 6-17

[131] 马荣华, 戴锦芳. 应用实测光谱估测太湖梅梁湾附近水体叶绿素浓度. 遥感学报, 2005, 9(1): 78-86.

[132] 段洪涛, 张 柏, 宋开山等. 查干湖叶绿素 a 浓度高光谱定量模型研究. 环境科学, 2006, 27(3): 503-507.

[133] Duan H, Ma R, Zhang B et al. Determination of chlorophyll-a concentration using inverse continuum removal analysis of fluorescence peak in Lake Chagan, China. Proceedings of SPIE, 2007: 6752.

[134] 雷 坤, 郑丙辉, 王 桥. 基于中巴地球资源 1 号卫星的太湖表层水体水质遥感. 环境科学学报, 2004, 24(3): 376-380.

[135] 唐军武, 马超飞, 牛生丽等. CBERS-02 卫星 CCD 相机资料定量化反演水体成分初探. 中国科学(E 辑), 2005, 35(增刊 I ): 156-170.

[136] Duan H, Zhang Y, Zhang B et al. Assessment of chlorophyll-a concentration and trophic state for Lake Chagan using Landsat TM and field spectral data. Environmental Monitoring and Assessment, 2007, 129: 295-308.

[137] Duan H, Zhang Y, Zhang B et al. Estimation of chlorophyll-a concentration and trophic states for inland lakes in Northeast China from Landsat TM data and field spectral measurements. International Journal of Remote Sensing, 2008, 29(3): 767-786.

[138] Kahru M, Mitchell BG, Diaz A et al. MODIS detects a devastating algal bloom in Paracas Bay, Peru. EOS, 2004, 85(45): 465-467.

[139] 万幼川, 黄家洁, 刘良明. 基于 MODIS 数据的二类水体叶绿素反演算法理论与实现. 武汉大学学报(信息科学版), 2004, 24(3): 376-380.

[140] Kutser T, Metsamaa L, Bahtmäe E et al. Suitability of MODIS 250m resolution band data for quantitative mapping of cyanobacterial blooms. Proc Estonian Acad Sci Biol Ecol, 2006, 55(4): 318-328.

[141] 王艳红, 马荣华, 郑正栋. 基于分区的太湖叶绿素 a 遥感估测模型. 河海大学学报(自然科学版), 2007, 35(1): 86-91.

[142] Wang M, Shi W. Satellite-observed algae blooms in China’s Lake Taihu. EOS, 2008, 89(22): 201-202.

[143] Siegel DA, O’Brien MC, Sorensen JC et al. Results of the SeaWiFS Data Analysis Round-Robin (DARR-94), July 1994. In: Hooker SB, Firestone ER eds. NASA Technical Memorandum 104566. Maryland: NASA Goddard Space Flight Center, 1995.

[144] Kaufman YM, Sendra C. Algorithm for automatic atmospheric correction to visible and near-infrared satellite imagery. International Journal of Remote Sensing, 1988, 30: 231-248.

[145] Chavez PS. An improved dark-object subtraction technique for atmospheric scattering correction of multispectral data. Remote Sensing of Environment, 1988, 24: 459-479.

[146] Kruse FA. Comparison of ATREM, ACORN, and FLAASH Atmospheric Corrections Using Low - altitude AVIRIS Data of Boulder, Co. In proceedings 13th JPL Airborne Geoscience Workshop. Jet Propulsion Laboratory, Pasadena, CA, 2004.

[147] Rast MS, Hook J, Elvidge CD. An evaluation of techniques for the extraction of mineral absorption features from high spectral resolution remote sensing data. Photogrammetric Engineering and Remote Sensing, 1991, 57(10): 1303-1309.

[148] Lee Z, Carder KL, Du K. Effects of molecular and particle scattering on the model parameter for remote-sensing reflectance. Appl Opt, 2004, 43(25): 4957-4964.

[149] IOCCG (International Ocean Color Coordinating Group). Remote sensing of ocean color in coastal and other optically-complex waters. In: Sathyendranath S ed. Reports of the international ocean color coordinating group, No.3. Dartmouth, Canada, 2000(http://www.ioccg.org.). 